\title{
Relation Between Efficacy of Radiofrequency Catheter Ablation and Site of Origin of Idiopathic Ventricular Tachycardia
}

\author{
Hugh Calkins, MD, Steven J. Kalbfleisch, MD, Rafel El-Atassi, MD, \\ Jonathan J. Langberg, MD, and Fred Morady, MD
}

The results of radiofrequency catheter ablation of ventricular tachycardia (VT) in patients without structural heart disease are reported. Particular attention was focused on the relation between efficacy and the site of origin of the VT. Eighteen consecutive patients ( 5 women and 13 men; mean age $41 \pm 13$ years) with idiopathic VT underwent catheter ablation using radiofrequency energy. Sites for radiofrequency energy delivery were selected on the basis of pace mapping. A follow-up electrophysiologic test was performed 1 to 3 months after the ablation procedure. Twenty $\mathbf{V}$ were induced. Radiofrequency catheter ablation was successful in eliminating all $10 \mathrm{VTs}$ originating from the right ventricular outflow tract, and 5 of 10 from other sites in the left or right ventricle. There were no complications. The duration of ablation sessions was shorter, the frequency of identifying a site resulting in an identical pace map was higher, and the efficacy of catheter ablation was greater for VTs originating from the right ventricular outflow tract than for those from other locations. The results of this study demonstrate that radiofrequency catheter ablation of idiopathic VT is safe and effective. The efficacy of the procedure is dependent on the site of origin of the VT, with the efficacy being greater for VTs originating from the outflow tract of the right ventricle than for those from other locations.

(Am J Cardiol 1993;71:827-833)

From the Division of Cardiology, University of Michigan Medical Center, Ann Arbor, Michigan. Manuscript received September 14, 1992; revised manuscript received and accepted October 16, 1992.

Address for reprints: Hugh Calkins, MD, Division of Cardiology, Carnegie Room 530, Johns Hopkins Hospital, 600 N. Wolfe Street, Baltimure, Maryland 21287.
7 wo recent studies reported that direct-current and radiofrequency catheter ablation in patients without structural heart disease is effective in $>80 \%$ of patients. ${ }^{1,2}$ However, in both studies, all patients had 1 type of inducible ventricular tachycardia (VT) that originated most often in the outflow tract of the right ventricle. Therefore, little data are available on the efficacy of catheter ablation of idiopathic VT originating at sites other than at the right ventricular outflow tract. The present sludy reports the results of radiofrequency catheter ablation of VT in 18 consecutive patients without structural heart disease who underwent this procedure at the University of Michigan Medical Center. Particular attention was focused on the relation between efficacy and the site of origin of the VT.

\section{METHODS}

Characteristics of patients: The study comprised 18 patients ( 5 women and 13 men; mean age $41 \pm 13$ years, range 19 to 61 ) without structural heart disease who were referred for management of idiopathic VT and underwent catheter ablation using radiofrequency energy. The symptoms of VT consisted of presyncope in 4 patients, and palpitations in 14. No patient had history of syncope or cardiac arrest. Two patients were referred for evaluation after their first episode of VT. The mean duration of symptoms in the remaining 16 patients was $9 \pm 8$ years (range 1 month to 27 years). Five patients had $>20$ episodes of symptomatic VT monthly, and the mean number of episodes monthly in the remaining 11 paticnts was $5 \pm 3$. VT was documcnted to be sustained in 13 patients, and nonsustained (10 to 30 beats) in 5 . The clinically documented VT had a left bundle branch block pattern in 14 patients, and a right bundle branch block pattern in 4 . Thirteen patients previously had unsuccessful treatment or were intolerant to treatment with a mean of $2.1 \pm 0.6$ antiarrhythmic agents.

Each patient had a normal physical examination, and normal systolic and diastolic function on a 2-dimensional echocardiogram. One patient had evidence of mitral valve prolapse. Sixteen patients had a normal electrocardiogram, and 2 had either complete or incomplete right bundle branch block. Eleven patients had undergone an exercise treadmill test that showed no evidence of ischemia. Cardiac catheterization was performed in the 2 patients who were aged $>55$ years, and showed normal ventricular function and no coronary artery obstructions. Both patients with multiple morphologies of inducible VT also underwent a gated blood pool scan that showed nomal right and left ventricular function. 
No patient underwent a right ventricular endomyocardial biopsy.

Electrophysiologic testing: Electrophysiologic tests were performed in the fasting state $\geq 24$ hours after discontinuation of all antiarrhythmic agents. Informed consent was obtained under an investigational protocol approved by the Human Research Committee at the University of Michigan. Three $6 \mathrm{Fr}$ quadripolar electrode catheters (USCI) with $1 \mathrm{~cm}$ interelectrode spacing were inserted in a femoral vein, and positioned in the high right atrium, His bundle position and right ventricle. An initial bolus of 3,000 units of heparin was administered intravenously after placement of intracardiac catheters. Fentanyl or medazolam, or both, were administered intravenously during the procedure if needed for sedation. Leads $V_{1}$, I and III, and the intracardiac electrograms were recorded on a Siemens-Elema Mingograf 7 recorder at paper speeds of 25 or $100 \mathrm{~mm} / \mathrm{s}$. Bipolar electrograms from the distal pair of electrodes of the ablation catheter were amplified at a gain setting of 2 $\mathrm{cm} / \mathrm{mV}$, filtered at 50 to $500 \mathrm{~Hz}$ and recorded at paper speeds of $100 \mathrm{~mm} / \mathrm{s}$. A 12-lead electrocardiogram was recorded each time VT was induced and during pace

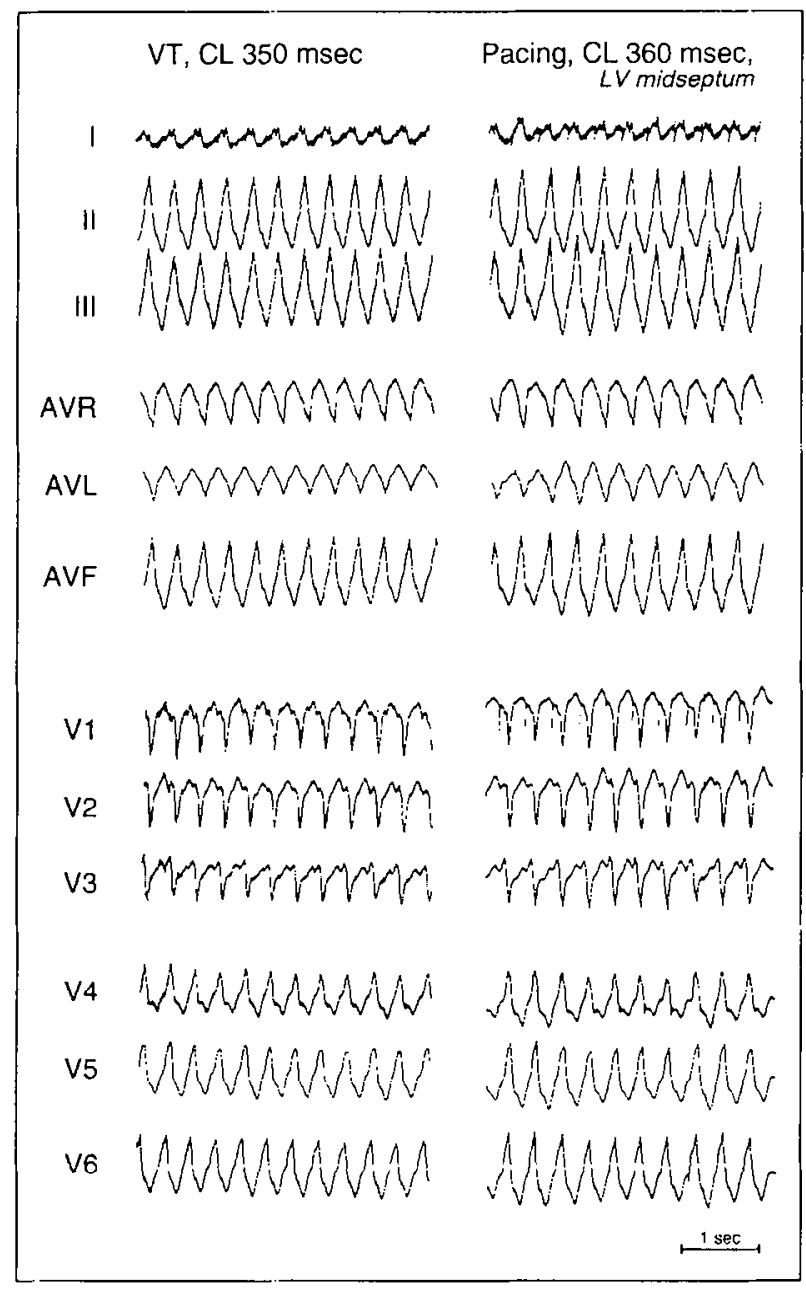

FGURE 1. Representative example of 12/12 pace map. Left, 12tead eloctrocardiogram recorded during vemtricular tachy cardia (VT) in patient 16. Pacins at similar cycle length (CL) from posteromedial aspect of left ventricle resulted in near identical pace map. Delivery of radiofrequency energy at this site was successful. LV = len ventricular. mapping. Pacing was performed with a programmable stimulator (Bloom Associates, Ltd.) using stimuli that were twice the diastolic threshold and $2 \mathrm{~ms}$ in duration. Atrial and ventricular pacing were performed at progressively shorter cycle lengths between 600 and 240 ms. Programmed stimulation then was performed at the apex of the right ventricle using up to 3 extrastimuli and drive train cycle lengths of 350,400 and $600 \mathrm{~ms}$. If sustained VT was not induced, the catheter was repositioned at the outflow tract of the right ventricle, and the pacing protocol was repeated. The stimulation protocol was repeated after an infusion of isoproterenol (2 to 4 $\mu \mathrm{g} / \mathrm{min}$ ) if sustained VT was not induced during baseline conditions. Sustained VT was defined as VT lasting $>30$ seconds, and nonsustained as VT $>6$ beats and $<30$ seconds in duration.

Based on the mode of induction and termination of VT, the mechanism of VT was presumptively categorized as being due to reentry, triggered activity or abnormal automaticity. For purposes of this study, VT that was reproducibly induced and terminated with premature stimuli was classified as reentrant. VT that was induced with a critical range of atrial or ventricular burst pacing, or both, was classified as due to triggered activity, and VT initiated spontaneously during an isoproterenol infusion was classified as automatic.

Mapping of ventricular tachycardia: Mapping was initiated in the right ventricle if the VT had a left bundle branch block pattern and in the left ventricle if it had a right bundle branch block pattern. Mapping efforts were concentrated to the inferior/basal wall of the right or left ventricle for VTs with a superior axis and to the anterior wall/outflow tract for those with an inferior axis.

Detailed mapping was performed with the ablation catheter, which was a 7Fr quadripolar electrode catheter with a $4 \mathrm{~mm}$ distal electrode, an interelectrode spacing of $2 \mathrm{~mm}$, and a deflectable curve (Mansfield-Webster or EP Technologies, Inc.). For mapping of the right ventricle, the catheter used to record the His bundle electrogram was removed and replaced with the ablation catheter. If mapping of the left ventricle was necessary, an 8Fr sheath was placed in a femoral artery, and the ablation catheter was positioned in the left ventricle by crossing the aortic valve. A 5,000-unit bolus of heparin was administered before mapping of the left ventricle, followed by 1,000 units/hour during the mapping process.

The primary mapping technique was pace mapping. Bipolar pacing at a current strength of twice the diastolic threshold was performed during sinus rhythm or VT, or both. The pacing rate was similar to the $V T$ rate when pace mapping was performed during sinus rhythm. A pacing rate slightly faster than the VT rate was used when pace mapping was performed during VT. If pacing was performed during VT, care was taken to be certain that there was no evidence of entrainment. Pace maps were graded on a scale of 0 to 12 based on the number of leads that showed a minor or major change in QRS morphology, and a change in amplitude of the electrogram $>2 \mathrm{mV}$. Minor configuration differences that were screened for included the following: (1) the appearance or disappearance of a notch, (2) the appearance or 
disappearance of a Q, R or S wave that was $<25 \%$ of the peak-to-peak QRS amplitude, (3) a change in the ratio of the amplitude of individual components to the total QRS amplitude $>25$ but $<50 \%$, and (4) a change in the shape of a major component - either a marked change in slope upstroke or a change in the configuration of the peak. ${ }^{3,4}$ Major configuration differences that were screened for included the following: (1) the appearance or disappearance of a component that was $>50 \%$ of the total QRS amplitude, and (2) a change in the amplitude of a component of the QRS complex $>50 \%$ of the total QRS amplitude.

Mapping based on the timing of local ventricular activation was not routinely performed in these patients. However, the onset of the local electrogram in relation to the QRS complex was recorded in patients in whom mapping was performed during VT.

Catheter ablation protocol: Catheter ablation was performed using radiofrequency energy delivered as a continuous, unmodulated sine wave at 350 or $500 \mathrm{kHz}$ (Radionics RFG-3B, Burlington, Massachusetts, or EP Technologies, Inc., Sunnyvale, California) between the distal electrode of the ablation catheter and a large adhesive skin electrode positioned over the left scapula. An identical (12/12) pace map was the primary criterion used to identify sites for radiofrequency energy delivery (Figure 1). If a site resulting in a 12/12 pace map was not found, radiofrequency energy was delivered at the site demonstrating the best pace map. Twenty-five to 35 W were delivered for 30 to 60 seconds or until a sudden increase in impedance indicative of coagulum formation. Radiofrequency current was delivered during sinus rhythm or VT (Figure 2). If VT could be reinduced after the application of radiofrequency current, the catheter was repositioned. If ongoing VT was terminated by the application of radiofrequency current or if VT could not be induced after the first application, a second application was delivered. In the event of an impedance
FGURE 2. Delivery of radiofrequency (RF) energy at successful ablation site during sustained ventricular tachycardia. Six limb leads and power (Watts) of RF energy used for ablation are shown. Sustained ventricular tachycardia terminat. ed 6 seconds after onset of RF energy delivery.
FGURE 3. Schematic drawing of heart showing site of origin of 20 ventricular tachycardias for which radiofiequency catheter ablation was attempted. $X$, ventricular tachycardias that were successfully ablated. Closed circles, ventricular tachycardias that were not successfully ablated. Ten ventricular tachycardias were located in outflow tract of right ventricle, and 10 were located at other sites in left and right ventricles.
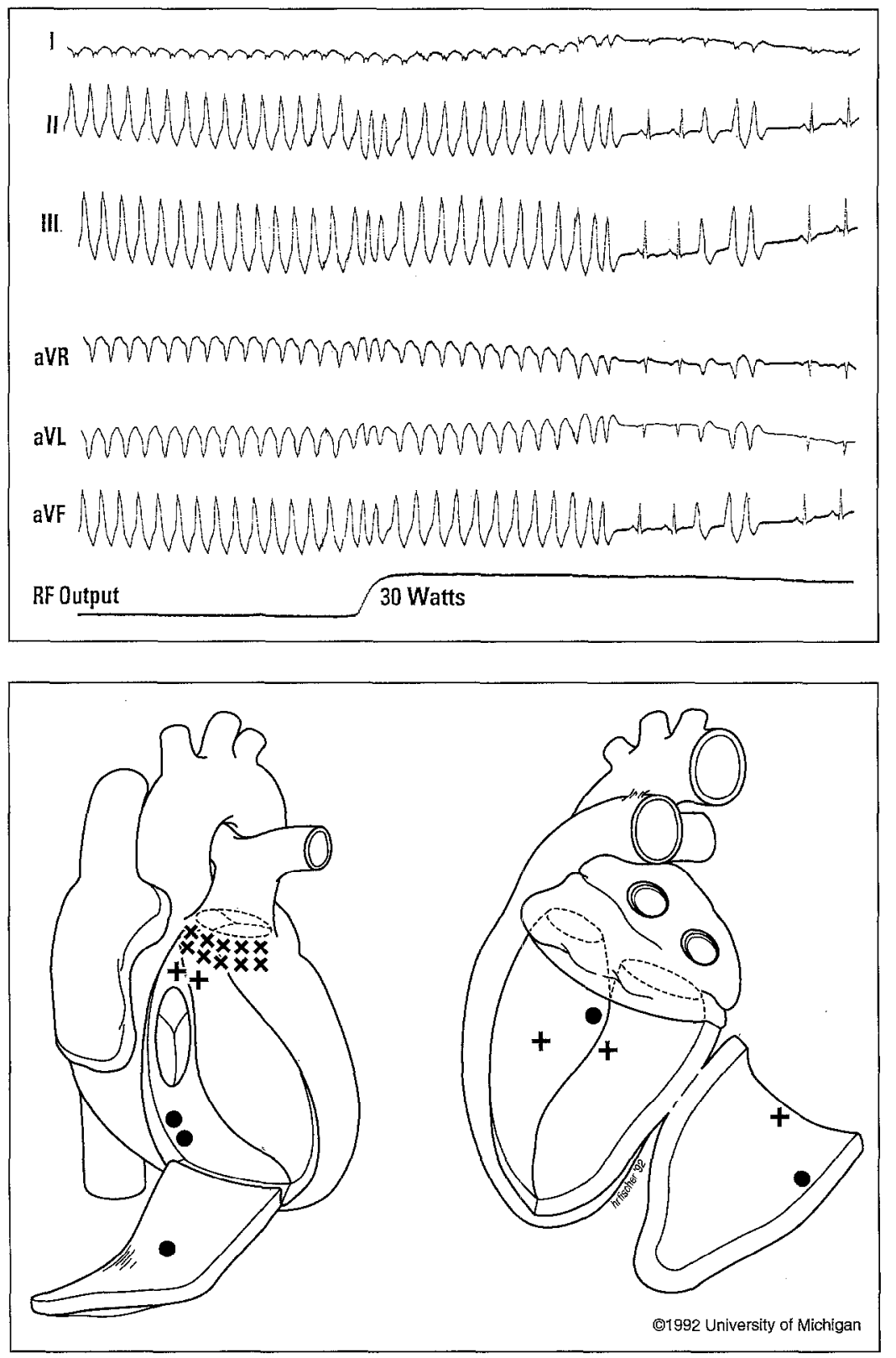


\begin{tabular}{|c|c|c|c|c|c|c|c|c|c|c|c|}
\hline Pt. & $\begin{array}{c}\text { VT } \\
\text { Induced }\end{array}$ & $\begin{array}{c}\text { VT } \\
\text { Morphology }\end{array}$ & $\begin{array}{l}\text { Cycle } \\
\text { Length } \\
\text { (ms) }\end{array}$ & $\begin{array}{c}\text { VT } \\
\text { Mechanism }\end{array}$ & $\begin{array}{c}\text { VT } \\
\text { Location }\end{array}$ & $\begin{array}{l}\text { No. } \\
\text { of RF } \\
\text { Sites }\end{array}$ & $\begin{array}{c}\text { Pace } \\
\text { Mapping }\end{array}$ & $\begin{array}{l}\text { Activation } \\
\text { Time }\end{array}$ & $\begin{array}{l}\text { Acute } \\
\text { Result }\end{array}$ & $\begin{array}{c}\mathrm{F} / \mathrm{U} \\
\text { (mos) }\end{array}$ & $\begin{array}{l}\text { Long- } \\
\text { Term } \\
\text { Results }\end{array}$ \\
\hline \multicolumn{12}{|c|}{ Ventricular Tachycardia Originating in Right Ventricular Outflow Tract } \\
\hline $\begin{array}{r}1 \\
2 \\
3 \\
4 \\
5 \\
6 \\
7 \\
8 \\
9 \\
10\end{array}$ & $\begin{array}{l}\text { S } \\
\text { S } \\
S \\
S \\
\text { NS } \\
\text { NS } \\
\text { NS } \\
\text { S } \\
\text { NS } \\
\text { S }\end{array}$ & $\begin{array}{l}\text { LBI } \\
\text { LBI } \\
\text { LBI } \\
\text { LBI } \\
\text { LBI } \\
\text { LBI } \\
\text { LBI } \\
\text { LBI } \\
\text { LBS } \\
\text { LBI }\end{array}$ & $\begin{array}{l}360 \\
240 \\
320 \\
300 \\
300 \\
320 \\
430 \\
340 \\
260 \\
260\end{array}$ & $\begin{array}{l}\text { Automatic } \\
\text { Reentrant } \\
\text { Automatic } \\
\text { Automatic } \\
\text { Triggered } \\
\text { Automatic } \\
\text { Automatic } \\
\text { Reentrant } \\
\text { Automatic } \\
\text { Triggered }\end{array}$ & $\begin{array}{l}\text { RVOT } \\
\text { RVOT } \\
\text { RVOT } \\
\text { RVOT } \\
\text { RVOT } \\
\text { RVOT } \\
\text { RVOT } \\
\text { RVOI } \\
\text { RVOT } \\
\text { RVOT }\end{array}$ & $\begin{array}{l}1 \\
1 \\
1 \\
1 \\
1 \\
1 \\
2 \\
1 \\
3 \\
2\end{array}$ & $\begin{array}{l}12 \\
12 \\
12 \\
12 \\
12 \\
12 \\
12 \\
12 \\
12 \\
12\end{array}$ & $\begin{array}{r}-25 \\
-10 \\
0 \\
0 \\
-35 \\
-10\end{array}$ & $\begin{array}{l}\text { Success } \\
\text { Success } \\
\text { Success } \\
\text { Success } \\
\text { Success } \\
\text { Success } \\
\text { Success } \\
\text { Success } \\
\text { Success } \\
\text { Success }\end{array}$ & $\begin{array}{r}12 \\
10 \\
10 \\
9 \\
7 \\
7 \\
7 \\
6 \\
4 \\
4\end{array}$ & $\begin{array}{l}\text { Success } \\
\text { Success } \\
\text { Success } \\
\text { Success } \\
\text { Success } \\
\text { Success } \\
\text { Success } \\
\text { Success } \\
\text { Success } \\
\text { Success }\end{array}$ \\
\hline \multicolumn{12}{|c|}{ Ventricular Tachycardia Originating from Other Location } \\
\hline $\begin{array}{r}11 \\
12 \\
13 \\
14 \\
14 \\
15 \\
16 \\
8 \\
17 \\
18\end{array}$ & $\begin{array}{l}\text { S } \\
S \\
S \\
S \\
S \\
N S \\
S \\
S \\
S \\
S\end{array}$ & $\begin{array}{l}\text { RBI } \\
\text { LBI } \\
\text { RBI } \\
\text { LBS } \\
\text { LBS } \\
\text { RBS } \\
\text { RBI } \\
\text { LBS } \\
\text { LBI } \\
\text { LBnl }\end{array}$ & $\begin{array}{l}270 \\
340 \\
390 \\
260 \\
290 \\
360 \\
350 \\
300 \\
300 \\
350\end{array}$ & $\begin{array}{l}\text { Automatic } \\
\text { Reentrant } \\
\text { Automatic } \\
\text { Reentrant } \\
\text { Reentrant } \\
\text { Automatic } \\
\text { Reentrant } \\
\text { Reentrant } \\
\text { Reentrant } \\
\text { Reentrant }\end{array}$ & $\begin{array}{l}\text { LV, antbasal } \\
\text { RV, inflow } \\
\text { LV, antmedial } \\
\text { RV, postbasal } \\
\text { RV, postbasal } \\
\text { LV, postmed } \\
\text { LV, midseptum } \\
\text { LV, posteroseptal } \\
\text { RV, inflow } \\
\text { RV, midant }\end{array}$ & $\begin{array}{r}1 \\
1 \\
0^{\star} \\
24 \\
8 \\
3 \\
7 \\
26 \\
6 \\
14\end{array}$ & $\begin{array}{r}12 \\
12 \\
10 \\
9 \\
8 \\
12 \\
10 \\
12 \\
12\end{array}$ & $\begin{array}{l}-25 \\
-30\end{array}$ & $\begin{array}{l}\text { Success } \\
\text { Success } \\
\text { Failure } \\
\text { Failure } \\
\text { Failure } \\
\text { Success } \\
\text { Success } \\
\text { Failure } \\
\text { Success } \\
\text { Failure }\end{array}$ & $\begin{array}{r}13 \\
10 \\
9 \\
8 \\
8 \\
7 \\
6 \\
6 \\
5 \\
4\end{array}$ & $\begin{array}{l}\text { Success } \\
\text { Success } \\
\text { Failure } \\
\text { Failure } \\
\text { Failure } \\
\text { Success } \\
\text { Success } \\
\text { Failure } \\
\text { Success } \\
\text { Failure }\end{array}$ \\
\hline $\begin{array}{r}{ }^{* N O} \\
\mathrm{~F} / \mathrm{U} \\
\text { nonsus } \\
\text { ventric }\end{array}$ & $\begin{array}{l}\text { ffrequency } \\
\text { Ilow-up; } \\
\text { d; RBI = } \\
\text { tachycardi }\end{array}$ & $\begin{array}{l}\text { plications delive } \\
=\text { left bundle in } \\
\text { it bundle inferior }\end{array}$ & i $\mathrm{RBS}=$ & $\begin{array}{l}\text { atheter instabili } \\
=\text { left bundle } n \\
\text { t bundle superi }\end{array}$ & $\begin{array}{l}\text { phology VT with an } R \\
\text { xis; } R F=\text { radiofreque }\end{array}$ & $\begin{array}{l}\text { tio in le } \\
\mathrm{RV}=\mathrm{ri}\end{array}$ & $\begin{array}{l}\text { aVF of } 1 ; \\
\text { ventricle; } F\end{array}$ & $\begin{array}{l}=\text { left bundl } \\
\mathrm{T}=\text { right ven }\end{array}$ & $\begin{array}{l}\text { perior axis } \\
\text { lar outflor }\end{array}$ & $\begin{array}{l}=\text { left } \\
\text { t; } S=\end{array}$ & $\begin{array}{l}\text { tricle; } N S= \\
\text { ained; } V T=\end{array}$ \\
\hline
\end{tabular}

increase, the catheter was withdrawn and the coagulum was removed from the catheter tip. Twenty-five to 30 minutes after ablation of VT, the absence of inducible VT was confirmed before removing all catheters and sheaths.

In each patient, the time needed for inserting and positioning catheters, the diagnostic component of the electrophysiologic test, and the catheter ablation procedure were recorded.

Postablation monitoring and evaluation: After the procedure, patients underwent telemetric electrocardiographic monitoring for 2 to 4 days. Creatine kinase and MB isoenzyme concentrations were measured every 8 hours for 24 hours after the ablation procedure, and a 2-dimensional echocardiogram was obtained the day after the procedure. The type of follow-up testing performed before discharge depended on the mode of induction of VT during the baseline electrophysiologic test. Electrophysiologic testing was performcd in patients in whom VT had been initiated by pacing or by programmed stimulation before ablation. An exercise treadmill test was performed or an isoproterenol infusion administered in patients in whom VT had been initiated only during exercise or by an isoproterenol infusion before ablation.

Follow-up: Each patient was observed on a regular basis every 2 to 6 months by 1 of the authors or by the referring physician. Each patient was also interviewed by telephone to obtain follow-up information. The type of follow-up testing that was performed before discharge from the hospital was also performed 1 to 3 months later to assess the long-term response to catheter ablation. In
1 patient who had history of daily episodes of symptomatic, nonsustained VT and in an additional one who refused to undergo a follow-up electrophysiologic test, a successful outcome was defined as the absence of VT on a Holter monitor and as the absence of symptoms of VT.

Statistical analysis: Continuous variables are expressed as mean \pm 1 SD. Comparison of VT characteristics, ablation variables and predictors of outcome was performed using a Student's $t$ test or contingency table analysis. A p value $<0.05$ was considered significant.

\section{RESULTS}

Characteristics of ventricular tachycardia: Twenty monomorphic VTs were induced in the 18 patients in this study. Sixteen patients had 1 morphology of VT, and 2 patients had 2 morphologies. The mean VT cycle length was $318 \pm 51 \mathrm{~ms}$ (range 260 to 430 ). The VT was nonsustained in 4 patients and sustained in 14. The mechanism of VT was automatic in $10 \mathrm{VTs}$, reentrant in 8 , and triggered in 2 . Figure 3 shows the site of origin of the VTs. Ten VTs were located in the outflow tract of the right ventricle and 10 at other sites in the left or right ventricle.

Ventricular tachycardia originating in the right ventricular outflow tract: Radiofrequency catheter ablation was successful in eliminating the 10 VTs that originated in the outflow tract of the right ventricle (100\%; Table I); this was the only type of VT in 9 patients. The tenth patient also had a second type of VT induced, which originated in the posteroseptal area of the left ventricle, and was not successfully ablated. All patients in whom 


\begin{tabular}{|c|c|c|c|}
\hline Parameter & $\begin{array}{c}\text { RVOT } \\
(n=10)\end{array}$ & $\begin{array}{c}\text { Other } \\
\text { Sites } \\
(n=10)\end{array}$ & $\begin{array}{c}p \\
\text { Value }\end{array}$ \\
\hline \multicolumn{4}{|l|}{ VT characteristics } \\
\hline VT cycle length (ms) & $315 \pm 32$ & $321 \pm 30$ & NS \\
\hline \multicolumn{4}{|l|}{ VT mechanism } \\
\hline Reentrant & 2 & 7 & NS \\
\hline Automatic & 6 & 3 & \\
\hline Triggered & 2 & 0 & \\
\hline \multicolumn{4}{|l|}{ Ablation procedure } \\
\hline Pace map & & & $<0.01$ \\
\hline $12 / 12$ & 10 & 5 & \\
\hline$<12 / 12$ & 0 & 5 & \\
\hline Duration of procedure (min) & $73 \pm 17$ & $142 \pm 75$ & 0.03 \\
\hline Ablation results & & & $<0.01$ \\
\hline Success & 10 & 5 & \\
\hline Failure & 0 & 5 & \\
\hline
\end{tabular}

catheter ablation was acutely successful remained free of symptomatic tachycardia during a mean follow-up of 8 \pm 3 months (range 4 to 12 ).

Seven VTs were ablated with 1 application of radiofrequency energy, 2 needed 2 applications, and 1 needed 3 applications. The mean total procedure time was $83 \pm 17$ minutes (range 55 to 97 ).

Ventricular tachycardia originating from other sites: Radiofrequency catheter ablation was successful in eliminating 5 of 10 VTs $(50 \%)$ originating at sites other than the right ventricular outflow tract (Table I). Five of 9 patients $(56 \%)$ had all types of VT ablated; these patients remained free of symptomatic tachycardia during a mean follow-up of $8 \pm 3$ months (range 5 to 13). Two VTs were ablated with 1 application of radiofrequency energy delivery. The mean number of sites of radiofrequency energy delivery in the remaining 3 patients was $5 \pm 4$ (range 4 to 7 ).

Five VTs in 4 patients were not successfully ablated; 2 VTs originated from the posterobasal aspect of the right ventricle, 1 from the midanterior right ventricle, 1 from the posteroseptal left ventricle and 1 from the anteromedial left ventricle. A stable catheter position that resulted in a 12/12 pace map was identified in only 1 of 5 VTs that were not successfully ablated (patient 18). No applications of radiofrequency energy were delivered to patient 13 , because a stable catheter position at the site of the best pace map could not be obtained. Three of 4 patients in whom catheter ablation was unsuccessful have been treated with antiarrhythmic drugs. The fourth patient received an implantable cardioverter-defibrillator.

The mean procedure time was $142 \pm 75$ minutes (range 65 to 305), and the mean duration of successful ablation procedures was $102 \pm 51$ minutes (range 55 to 105).

Comparison of ventricular tachycardia originating in the right ventricular outfiow tract vensus other sites: Table II shows the VT characteristics and ablation procedure variables that were compared for VTs originat-

\begin{tabular}{|lccc|}
\hline \multicolumn{4}{|l|}{ TABLE III Comparison of Ventricular Tachycardias That Were } \\
Successfully and Unsuccessfully Ablated
\end{tabular}

ing in the right ventricular outflow tract versus other sites. Neither the rate nor the mechanism of VT was site dependent. However, the duration of the ablation procedures was shorter, the frequency of identifying a site resulting in a 12/12 pace map was higher, and the efficacy of the ablation procedure was greater for VTs originating in the right ventricular outflow tract than for those originating in other locations $(\mathrm{p}<0.03)$.

Predictors of success: Table III shows the factors evaluated as possible predictors of success. Neither the cycle length nor presumed mechanism of the VT was related to outcome. In contrast, the site of origin of the VT, and the ability to obtain a 12/12 pace map were associated with outcome $(p<0.01)$. Radiofrequency catheter ablation was successful for $93 \%$ of VTs for which a $12 / 12$ pace map could be achieved compared with only $20 \%$ of VTs for which a 12/12 pace map was not obtained.

Complications: No patient developed a complication. The mean peak creatine kinase concentration was $105 \pm 112 \mathrm{IU} /$ liter (normal 30 to 240). Two patients had an increase in the crealine kinase MB fraction (patients 12 and $14 ; 16$ and 30 IU/liter, respectively; normal 0 to 10). The number of applications of radiofrequency energy delivered in the 2 patients with an increase in creatine kinase MB fraction was no different from that in the other 16. No patient had a pericardial effusion or wall motion abnormality on the echocardiogram obtained after the ablation procedure.

\section{DISCUSSION}

Main findings: The results of this study show that radiofrequency catheter ablation of idiopathic VT is feasible and safe, but that the efficacy is significantly greater when VT originates in the right ventricular outflow tract than at other sites in the right or left ventricle. Whereas $100 \%$ of VTs originating in the right ventricular outflow were successfully ablated in this series, the success rate was only $50 \%$ for those originating at other sites in the right or left ventricle.

Importance of site of onigin of idiopathic ventricular tachycardia: The success of radiofrequency catheter ablation of VT is dependent on accurate mapping of the VT, a stable catheter position, and a VT that is suscep- 
tible to ablation by the discrete and $<1 \mathrm{~cm}$ lesions created by radiofrequency energy. ${ }^{5}$ Therefore, the reduced efficacy of catheter ablation for VTs originating at sites other than the right ventricular outflow tract may have resulted from difficulty in mapping or stabilizing the ablation catheter, or resistance of the VT to ablation, or a combination.

The results of this study suggest that inadequate localization of the VT or inadequate stabilization of the ablation catheter, or both, was the most frequent reason for failure. A stable catheter position at which there was a 12/12 pace map was identified for all VTs originating in the right ventricular outflow tract, but for only $50 \%$ of those originating at other sites. This greater difficulty mapping VTs originating at sites other than the right ventricular outflow tract may be attributable to anatomic considerations. The steerable ablation catheter used in this study could be positioned in the right ventricular outflow tract relatively easily, whereas positioning ablation catheters at other sites in the right or left ventricle was more difficult. However, inadequate mapping was not the only reason for failure, because 1 VT that was due to reentry was not ablated despite delivering radiofrequency energy at sites at which a $12 / 12$ pace map was identified. This observation suggests that some VTs may not be susceptible to radiofrequency catheter ablation, because of the location or size of the VT site of origin, or both. It is also possible that the site targeted was not a critical component of the reentrant circuit and that an alternative mapping strategy such as entrainment or activation mapping would have identified a successful ablation site. ${ }^{6,7}$

Mapping technique: The $93 \%$ efficacy of radiofrequency catheter ablation of VT from sites at which a 12/12 pace map was obtained is consistent with our current understanding of the spatial resolution of pace mapping, and the size of lesions created during radiofrequency encrgy delivery. ${ }^{3-5,8}$ Kadish et al ${ }^{3,4}$ previously showed that the spatial resolution of uni- or bipolar pace mapping, using a current strength of twice the diastolic threshold and an interelectrode distance $<5 \mathrm{~mm}$, is approximately $5 \mathrm{~mm} \cdot{ }^{3}$ Therefore, the spherical lesions created with radiofrequency energy ${ }^{9}$ would be predicted to be effective in ablating a VT focus if delivered at a site at which a 12/12 pace map was obtained.

In this study, attempts were made to identify a site from which a 12/12 pace map based on amplitude and morphologic criteria was obtained for each VT. Therefore, the results of this study do not enable us to determine the efficacy of radiofrequency applications at sites with less accurate pace maps. However, a 12/12 pace map appears not to be essential for success, because 1 VT originating from the posterior medial left ventricle was ablated despite an $8 / 12$ pace map at that site. Because pace mapping was the primary mapping technique used in this study, the results do not enable us to compare the accuracy of pace mapping with that of mapping based on activation time.

Complications of radiofrequency catheter ablation: The absence of complications in this study is in accordance with the findings of prior studies that reported no major complications during catheter ablation of
VT using direct-current or radiofrequency energy in patients without structural heart disease.,2 The small number of patients in this series who had an increase in creatine kinase MB fraction is also similar to the findings of prior studies of catheter ablation of VT or accessory pathways using radiofrequency current. ${ }^{2,10}$ This most likely reflects the small size of lesions created with radiofrequency current, as well as the small number of radiofrequency applications that were delivered.

Comparison with prior studies: The results of this study confirm and extend those of previous reports of catheter ablation of VT in patients without structural heart disease. ${ }^{1,2}$ The high efficacy of catheter ablation in patients with idiopathic VT observed in this study is similar to that reported by other investigators using either direct-current ${ }^{1}$ or radiofrequency energy. ${ }^{2}$ However, the relation between the efficacy of catheter ablation and the site of origin of VT was not previously reported.

The $79 \%$ overall success rate achieved in this study is similar to the $80 \%$ efficacy of direct-current catheter ablation of VT in patients without structural heart disease that was reported from this institution. ${ }^{1}$ However, in contrast to the prior study, radiofrequency current was used as an energy source in this study. Although the efficacy appears to be similar, radiofrequency current may be a preferable energy source hecause the lesions are smaller and more circumscribed, ${ }^{9}$ and general anesthesia is not needed.

The efficacy of radiofrequency catheter ablation of VT in this series is less than the $94 \%$ success rate reported by Klein et al. ${ }^{2}$ This difference cannot be explained by technologic differences, because radiofrequency energy was used in both series, and the energy was delivered through steerable catheters with a $4 \mathrm{~mm}$ distal tip. The difference may reflect the reduced efficacy of radiofrequency catheter ablation of VTs originating at sites other than the outflow tract of the right ventricle. In both studics, all VTs originating from the right ventricular outflow tract were successfully ablated. The relation between the efficacy of radiofrequency catheter ablation and the site of origin of VT was not evaluated by Klein, because catheter ablation was attempted in only 4 VTs ( $25 \%$ of the cohort) originating from sites other than the right ventricular outflow tract. In contrast, in the present study, the relation between efficacy and the site of origin of VT could be evaluated, because 10 VTs (50\% of the cohort) originated at sites other than the right ventricular outflow tract.

Study limitations: Endomyocardial biopsies were not performed in any patients, and therefore we cannot exclude myocarditis or right ventricular dysplasia. However, all patients had normal systolic and diastolic function of the right and left ventricles on a 2-dimensional echocardiogram. Furthermore, both patients in whom multiple types of VT were induced also had a normal right ventricular ejection fraction based on a gated blood pool scan.

Acknowledgment: We thank the staff of the Clinical Electrophysiology Laboratory for assistance, and Vanessa J. Sims and Elaine R. Lowery for help in preparing this manuscript. 


\section{REFERENCES}

1. Morady F, Kadish AH, DiCarlo L, Kou WH, Winston S, de Buitleir M, Calkins $\mathrm{H}$, Rusentleck S, Suusa S. Long-teru results of calleter ablation of idiopathic right ventricular tachycardia. Circulation 1990;82:2093-2099.

2. Klein LS, Shih HT, Hackett FK, Zipes DP, Miles WM. Radiofrequency catheter ablation of ventricular tachycardia in patients without structural heart disease. Circulation 1992;85:1666-1674.

3. Kadish AH, Childs K, Schmaltz S, Morady F. Differences in QRS configuration during unipolar pacing from adjacent sites: implications for the spatial resolution of pace-mapping. $J$ Am Coll Cardiol 1991:17:143-151.

4. Kadish AH, Schmaltz S, Morady F. A comparison of QRS complexes resulting from unipolar and bipolar pacing: implications for pace-mapping. PACE 1991;14: 823-832.

5. Langberg JJ, Lee MA, Chin MC, Rosenqvist M. Radiofrequency catheter ablation: the effect of electrode size on lesion volume in vivo. PACE 1990;13:1242-1248.

6. Fitzgerald DM, Friday KJ, Wah J, Lazzara R, Jackman WM. Electrogram pat- terns predicting successful catheter ablation of ventricular tachycardia. Circulation 1988;77:806-814.

7. Morady F, Kadish A, Rosenhcck S, Calkins H, Kou WH, de Buitleir M, Sousa J. Concealed entrainment as a guide for catheter ablation of ventricular tachycardia in patients with prior myocardial infarction. J Am Coll Cardiol 1991;17:678-689.

8. Josephson ME, Waxman HL, Gardner MJ, Buxton AE. Ventricular activation during ventricular endocardial pacing. Role of pace-mapping to localize origin of ventricular tachycardia. Am J Cardiol 1982;50:11-22.

9. Huang S, Graham AR, I ee MI, Ring MF, Gomman GD, Schiffman R. Comparison of catheter ablation using radiofrequency versus direct current energy: biophysiocal, electrophysiologic and pathologic observations. J Am Coll Cardiol 1991; 18:1091-1097.

10. Calkins H, Langberg J, Sousa J, El-Atassi R, Leon A, Kou W, Kalbfleisch S, Morady F. Radiofrequency catheter ablation of accessory atrioventricular connections in 250 patients. Abbreviated therapeutic approach to Wolff-Parkinson-White syndrome. Circulation 1992;85:1337-1346. 